\title{
Edible flowers as sources of phenolic compounds with bioactive potential
}

\author{
Tânia C.S.P. Pires ${ }^{\mathrm{a}, \mathrm{b}}$, Maria Inês Dias ${ }^{\mathrm{a}, \mathrm{c}}$, Lillian Barros ${ }^{\mathrm{a}, *}$, Ricardo C. Calhelha ${ }^{\mathrm{a}}$, \\ Maria José Alves $^{\mathrm{a}, \mathrm{d}}$, M. Beatriz P.P. Oliveira ${ }^{\mathrm{c}}$, Celestino Santos-Buelga ${ }^{\mathrm{b}}$, Isabel C.F.R. Ferreira ${ }^{\mathrm{a}, *}$ \\ a Centro de Investigação de Montanha (CIMO), Instituto Politécnico de Bragança, Campus de Santa Apolónia, 5300-253 Bragança, Portugal \\ ${ }^{\mathrm{b}}$ Grupo de Investigación en Polifenoles (GIP-USAL), Facultad de Farmacia, Universidad de Salamanca, Campus Miguel de Unamuno $s / n$, 37007 Salamanca, Spain \\ ${ }^{\mathrm{c}}$ REQUIMTE/LAQV, Science Chemical Department, Faculty of Pharmacy of University of Porto, Rua Jorge Viterbo Ferreira, 228, 4050-313 Porto, Portugal \\ ${ }^{\mathrm{d}}$ School of Health, Polytechnic Institute of Bragança, Av. D. Afonso V, 5300-121 Bragança, Portugal
}

\section{A R T I C L E I N F O}

\section{Keywords:}

Edible flowers

Infusions

Phenolic compounds

Bioactivity

\begin{abstract}
A B S T R A C T
The edible flowers are widely used, but there is still a lot to be done in relation to its bioactive potential and its correlation with the presence of phenolic compounds. The aim of this study was determined the individual phenolic profile in the hydromethanolic extracts and infusion preparations of four different flower samples (Dahlia mignon, Rosa damascena 'Alexandria' and R. gallica 'Francesa' draft in R. canina, Calendula officinalis L., and Centaurea cyanus L.) and their bioactive potential (antioxidant, antiproliferative, and antibacterial capacity). All the studied flowers presented different profiles regarding their phenolic composition and revealed biological potential. The bioactive potential of the studied flowers was moderate, the hydromethanolic extracts of rose petals showed the best results for antioxidant and antibacterial assays, while the antiproliferative properties were only present in some of the tested cell lines, for the hydromethanolic extracts, in which dahlia and rose showed the best results. These results demonstrate that edible flowers can be used as a source of phenolic compounds with bioactive potential, which can be applied in the food sector, as foods and as sources natural ingredients.
\end{abstract}

\section{Introduction}

Chefs around the world strive to go beyond the ordinary as they prepare new recipes, garnishing their dishes with flowers or using them as ingredients in salads, soups, entrees, desserts, and drinks (Kou, Turner, \& Luo, 2012). Edible flowers add a fresh and exotic aroma, delicate flavour and a visual appeal that makes them increasingly used in gourmet cuisine. Dahlia mignon, Rosa damascena 'Alexandria' and $R$. gallica 'Francesa' draft in $R$. canina, Calendula officinalis L., and Centaurea cyanus L. are among the most popular edible flowers (Fernandes, Casal, Pereira, Saraiva, \& Ramalhosa, 2017). The consumption of various types of edible flowers provides health benefits to the consumer, since they are a good source of phytochemicals, including phenolic compounds (Fernandes et al., 2017). These compounds have been related to the prevention of chronic degenerative diseases, such as diabetes, cognitive decline, and cardiovascular disease, as well as different types of cancer through the inhibition of their initiation and progression by modulating genes involved in key regulation processes (Anantharaju, Gowda, Vimalambike, \& Madhunapantula, 2016; Gutiérrez-Grijalva et al., 2016). The flowers may contain a variety of these natural antioxidants such as phenolic acids and flavonoids, being their presence strongly related to their colour either directly (e.g., anthocyanins and other flavonoid pigments) or indirectly through the copigmentation processes (Brouillard, 1988; Kaisoon, Siriamornpun, Weerapreeyakul, \& Meeso, 2011).

Several plants and their products have been used in foods as a mode of natural preservative, flavoring agent as well as a remedy to treat some of the common illness in humans. This property of curing is attributed mainly to their antimicrobial activities. Use of natural plant derived antimicrobials can be highly effective in reducing the dependence on antibiotics, minimize the chances of antibiotic resistance in food borne pathogenic microorganisms as well as help in controlling cross-contaminations by food-borne pathogens (Mak, Chuah, Ahmad, \& Bhat, 2013).

The phenolic profile characterization, as also antioxidant and antitumor activities of calendula samples have been previously studied by (Miguel et al., 2016). As for rose samples (R. canina), there are some previous studies on the total phenolic composition (Kuś, Jerković, Tuberoso, Marijanović, \& Congiu, 2014), individual phenolic profile (Demir, Yildiz, Alpaslan, \& Hayaloglu, 2014; Guimarães et al., 2013), and antioxidant activity of fruits and flowers (Barros, Carvalho, \& Ferreira, 2011; Barros, Dueñas, Carvalho, et al., 2012; Hvattum, 2002),

\footnotetext{
* Corresponding authors.

E-mail addresses: lillian@ipb.pt (L. Barros), iferreira@ipb.pt (I.C.F.R. Ferreira).
} 
but there is no report regarding Rosa damascena 'Alexandria' and $R$. gallica 'Francesa' draft in $R$. canina. Regarding centaurea, only total phenolic composition has been studied (Kuś et al., 2014), while for dahlia, to the author's best knowledge, there are no previous reports on its phenolic composition or bioactive properties.

The main goal of the present study was to establish the phenolic profiles in hydromethanolic extracts and infusion preparations of four different flower samples (Dahlia mignon, Rosa damascena 'Alexandria' and R. gallica 'Francesa' draft in R. canina, Calendula officinalis L., and Centaurea cyanus L.), and to evaluate their bioactive potential, including antioxidant, antiproliferative, and antibacterial capacity.

\section{Materials and methods}

\subsection{Standards and reagents}

Acetonitrile (99.9\%) was of HPLC grade from Fisher Scientific (Lisbon, Portugal). Phenolic standards (apigenin-7-O-glucoside, caffeic acid, chlorogenic acid, hesperetin, isoliquiritigenin, isorhamnetin-3-Oglucoside, kaempferol-3-O-rutioside, naringenin, $p$-coumaric acid, quercetin-3-O-glucoside, quercetin-3-O-rutinoside) were from Extrasynthèse (Genay, France). Lipopolysaccharide (LPS), dexamethasone, sulforhodamine B, trypan blue, trichloroacetic acid (TCA), tris(hydroxymethyl)aminomethane (Tris), Trolox (6-hydroxy-2,5,7,8tetramethylchroman-2-carboxylic acid) and formic acid were purchased from Sigma-Aldrich (St. Louis, MO, USA). RAW 264.7 cells were from the ECACC ("European Collection of Animal Cell Culture") (Salisbury, UK), and DMEM from Hyclone (Logan, Utah, US). The Griess Reagent System Kit was purchased from Promega (Madison, WI, USA). Dulbecco's modified Eagle's medium (DMEM), hank's balanced salt solution (HBSS), fetal bovine serum (FBS), L-glutamine, trypsin-EDTA, penicillin/streptomycin solution $(100 \mathrm{U} / \mathrm{mL}$ and $100 \mathrm{mg} / \mathrm{mL}$, respectively) were purchased from Hyclone (Logan, Utah, USA). 2,2Diphenyl-1-picrylhydrazyl (DPPH) was obtained from Alfa Aesar (Ward Hill, MA, USA), $p$-Iodonitrotetrazolium chloride (INT) from Panreac Applichem (Barcelona, Spain), Tryptic Soy Broth (TSB) and MuellerHinton (MH) from Biolab ${ }^{\circledR}$ (Hungary). All other general laboratory reagents were purchased from Panreac Química S.L.U. (Barcelona, Spain). Water was treated in a Milli-Q water purification system (TGI Pure Water Systems, USA).

\subsection{Samples and preparation of hydromethanolic extracts and infusions}

The flower samples were supplied by the company RBR Foods, from Castro Daire (Portugal), as dry material to be used directly or for preparation of infusions. Petals of four different species were used in the present study: Dahlia mignon (commercial seeds mixture), Rosa damascena 'Alexandria' and $R$. gallica 'Francesa' draft in $R$. canina, Calendula officinalis L., and Centaurea cyanus L. These samples are designated throughout the manuscript by their common names: dahlia, rose, calendula, and centaurea, respectively. All the samples were reduced to a fine powder ( 20 mesh) and mixed to obtain homogenate samples. The authors previously studied their nutritional composition (Pires, Dias, Barros, \& Ferreira, 2017).

To prepare the hydromethanolic extracts, $1 \mathrm{~g}$ of each sample was submitted to extraction with a methanol:water mixture $(80: 20, \mathrm{v} / \mathrm{v}$; $30 \mathrm{~mL}$ ) at $25^{\circ} \mathrm{C}$ and $150 \mathrm{rpm}$ during $1 \mathrm{~h}$, followed by filtration through a Whatman filter paper No. 4. Afterwards, the residue was extracted with one additional portion of the hydromethanolic mixture and the combined extracts were evaporated under reduced pressure (rotary evaporator Büchi R-210, Flawil, Switzerland).

To prepare the infusions, boiling distilled water $(100 \mathrm{~mL}, \mathrm{pH} \mathrm{6.6)}$ at $100{ }^{\circ} \mathrm{C}$ was added to each sample $(1 \mathrm{~g})$ and left to stand at room temperature for $5 \mathrm{~min}$, Afterwards, the infusions were filtered $(0.22 \mu \mathrm{m})$.

Both preparations were frozen and then lyophilized in order to perform all the assays described below.

\subsection{Analysis of phenolic compounds}

The phenolic profile was determined in the lyophilized hydromethanolic extracts and infusions, which were re-dissolved at a concentration of $5 \mathrm{mg} / \mathrm{mL}$ in methanol:water $(80: 20$, v/v) and water, respectively. The analysis was performed using a LC-DAD-ESI/MSn (Dionex Ultimate 3000 UPLC, Thermo Scientific, San Jose, CA, USA) as previously described by Bessada, Barreira, Barros, Ferreira, and Oliveira (2016). Double online detection was performed using 280, 330 and $370 \mathrm{~nm}$ as preferred wavelengths for DAD and in a mass spectrometer (MS). The MS detection was performed in negative mode, using a Linear Ion Trap LTQ XL mass spectrometer (Thermo Finnigan, San Jose, CA, USA) equipped with an ESI source. The identification of the phenolic compounds was performed based on their chromatographic behaviour, UV-vis and mass spectra by comparison with standard compounds, when available, and by using data reported in the literature. For quantitative analysis, a calibration curve for each available phenolic standard was constructed based on the UV signal. For the identified phenolic compounds for which a commercial standard was not available, the quantification was performed through the calibration curve of the most similar available standard. The peaks were quantified based on the area of the peak by using a manual quantification methods, which is permitted by the software used. To integrate peaks a perpendicular line was drawn from the valley between the peaks to the baseline extended between the normal baseline before and after the group of peaks. The results were expressed as $\mathrm{mg} / \mathrm{g}$ of dry weight (dw).

\subsection{Evaluation of the bioactivities}

\subsubsection{Antioxidant activity}

The lyophilized hydromethanolic extracts and infusions were redissolved in methanol:water $(80: 20, \mathrm{v} / \mathrm{v})$ and water, respectively, to obtain stock solutions of $2.5 \mathrm{mg} / \mathrm{mL}$ and $20 \mathrm{mg} / \mathrm{mL}$, which were further diluted to obtain a range of concentrations $(10 \mathrm{mg} / \mathrm{mL}$ to $0.07 \mathrm{mg} / \mathrm{mL})$ for antioxidant evaluation by DPPH radical-scavenging (Hatano, Kagawa, Yasuhara, \& Okuda, 1988), reducing power (Oyaizu, 1986) and inhibition of $\beta$-carotene bleaching assays (Shon, 2003). The final results were expressed as $\mathrm{EC}_{50}$ values $(\mu \mathrm{g} / \mathrm{mL})$, sample concentration providing $50 \%$ of antioxidant activity (for DPPH assay $50 \%$ of radical scavenge, 0.5 of absorbance in the reducing power assay and for $\beta$ carotene assay $50 \%$ of $\beta$-carotene bleaching inhibition). Trolox was used as positive control.

\subsubsection{Antibacterial activity}

The antibacterial activity was determined in the lyophilized hydromethanolic extracts and infusions, being re-dissolved in water in order to obtain a stock solution of $100 \mathrm{mg} / \mathrm{mL}$, and then submitted to further dilutions. The microorganisms used were clinical isolates from patients hospitalized in various departments of the Local Health Unit of Bragança and Hospital Center of Trás-os-Montes and Alto-Douro Vila Real, Northeast of Portugal. Seven Gram-negative bacteria (Escherichia coli, E. coli ESBL (extended spectrum of beta-lactamase), Klebsiella pneumoniae, K. pneumoniae ESBL, Morganella morganii, Pseudomonas aeruginosa, and Acinetobacter baumannii, isolated from urine and expectoration) and five Gram-positive bacteria (MRSA- methicillin-resistant Staphylococcus aureus, MSSA- methicillin-susceptible Staphylococcus aureus, Staphylococcus aureus, Listeria monocytogenes, and Enterococcus faecalis) were used to screen the antibacterial activity Minimum Inhibitory Concentrations (MIC) determinations were performed by the microdilution method and the rapid $p$-iodonitrotetrazolium chloride (INT) colorimetric assay following the methodology proposed by Kuete, Ango, et al. (2011) and Kuete, Kamga, et al. (2011) with some modifications. MIC was defined as the lowest concentration that inhibits the visible bacterial growth. Three negative controls were prepared (one with Mueller-Hinton Broth (MHB)/Tryptic Soy Broth (TSB), another one with the extract, and the third with medium and 


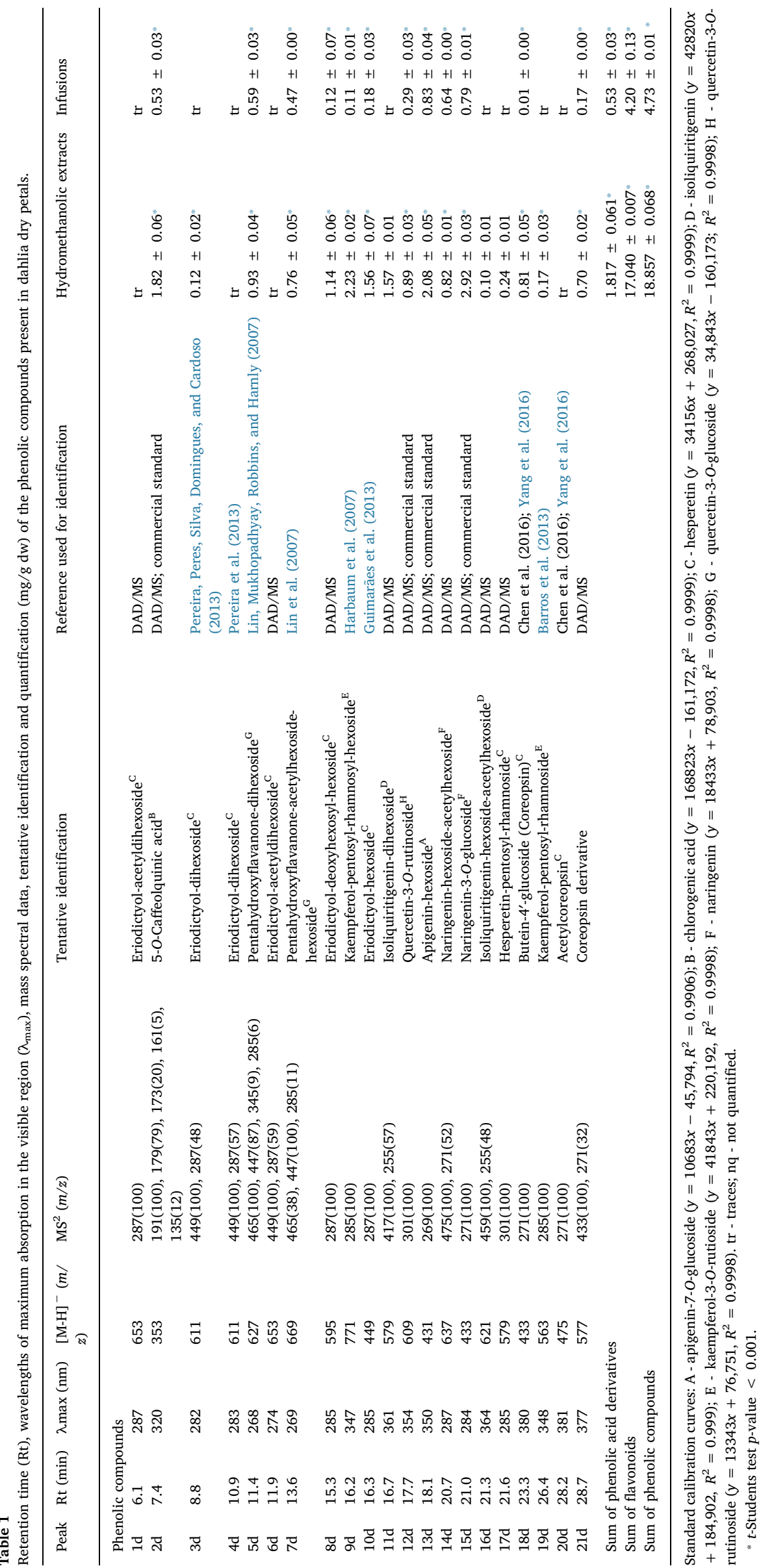


Table 2

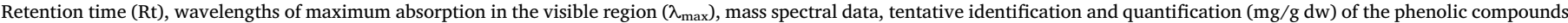
present in rose dry petals.

\begin{tabular}{|c|c|c|c|c|c|c|c|c|}
\hline Peak & Rt (min) & $\begin{array}{l}\lambda \max \\
(\mathrm{nm})\end{array}$ & $\begin{array}{l}{[\mathrm{M}-\mathrm{H}]^{-}(\mathrm{m} /} \\
z)\end{array}$ & $\operatorname{MS}^{2}(m / z)$ & Tentative identification & Reference used for identification & Hydromethanolic extracts & Infusions \\
\hline \multicolumn{9}{|c|}{ Phenolic compounds } \\
\hline $1 \mathrm{r}$ & 18.2 & 348 & 477 & $301(100)$ & Quercetin-glucuronide $^{\text {B }}$ & Guimarães et al. (2013) & $0.79 \pm 0.03^{*}$ & $0.49 \pm 0.01^{*}$ \\
\hline $2 \mathrm{r}$ & 18.6 & 355 & 463 & $301(100)$ & Quercetin-hexoside ${ }^{B}$ & Guimarães et al. (2013) & $1.37 \pm 0.04$ & $0.73 \pm 0.01$ \\
\hline $3 r$ & 19.0 & 355 & 463 & $301(100)$ & Quercetin-3-O-glucoside ${ }^{\mathrm{B}}$ & DAD/MS; commercial standard & $2.87 \pm 0.07$ & $1.31 \pm 0.01 *$ \\
\hline $4 \mathrm{r}$ & 21.1 & 348 & 593 & $285(100)$ & Kaempferol-3-O-rutinoside ${ }^{\mathrm{A}}$ & DAD/MS; commercial standard & $\operatorname{tr}$ & $\operatorname{tr}$ \\
\hline $5 r$ & 21.6 & 353 & 433 & $301(100)$ & Quercetin-pentoside $^{B}$ & Guimarães et al. (2013) & $0.66 \pm 0.01^{*}$ & $0.47 \pm 0.01^{*}$ \\
\hline $6 r$ & 22.0 & 348 & 461 & $285(100)$ & Kaempferol-glucuronide ${ }^{\mathrm{A}}$ & Guimarães et al. (2013) & $\operatorname{tr}$ & $\operatorname{tr}$ \\
\hline $7 r$ & 22.5 & 348 & 447 & $285(100)$ & Kaempferol-3-O-glucoside ${ }^{\mathrm{A}}$ & DAD/MS; commercial standard & $2.74 \pm 0.06$ & $0.88 \pm 0.01 *$ \\
\hline $8 \mathrm{r}$ & 25.1 & 348 & 417 & $285(100)$ & Kaempferol-pentoside ${ }^{\mathrm{A}}$ & $\begin{array}{l}\text { Barros, Dueñas, Ferreira, et al. } \\
\text { (2011) }\end{array}$ & $\operatorname{tr}$ & $\operatorname{tr}$ \\
\hline $9 \mathrm{r}$ & 25.9 & 347 & 417 & $285(100)$ & Kaempferol-pentoside ${ }^{\mathrm{A}}$ & $\begin{array}{l}\text { Barros, Dueñas, Ferreira, et al. } \\
\text { (2011) }\end{array}$ & $\operatorname{tr}$ & nd \\
\hline $10 \mathrm{r}$ & 27.2 & 348 & 431 & $285(100)$ & Kaempferol-rhamnoside ${ }^{\mathrm{A}}$ & $\begin{array}{l}\text { Barros, Dueñas, Ferreira, et al. } \\
\text { (2011) }\end{array}$ & $0.29 \pm 0.02$ & $\operatorname{tr}$ \\
\hline $11 \mathrm{r}$ & 30.1 & 314 & 609 & $463(100), 301(12)$ & $\begin{array}{l}\text { Quercetin-(p-coumaroyl) } \\
\text { hexoside }^{\mathrm{B}}\end{array}$ & Barros et al. (2013) & $0.46 \pm 0.01^{*}$ & $0.37 \pm 0.00$ \\
\hline $12 \mathrm{r}$ & 33.1 & 314 & 593 & 447(9),285(100) & $\begin{array}{l}\text { Kaempferol-(p-coumaroyl) } \\
\text { hexoside }^{\mathrm{A}}\end{array}$ & Guimarães et al. (2013) & $\operatorname{tr}$ & $\operatorname{tr}$ \\
\hline \multicolumn{7}{|c|}{ Sum of phenolic compounds (flavonoids) } & $9.18 \pm 0.23^{*}$ & $4.24 \pm 0.01 *$ \\
\hline
\end{tabular}

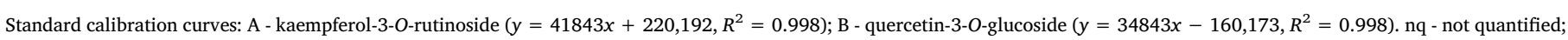
tr-traces.

${ }^{*} t$-Students test $p$-value $<0.001$.

antibiotic). One positive control was prepared with MHB and each inoculum. For the Gram-negative bacteria, antibiotics, such as amikacin, tobramycin, amoxicillin/clavulanic acid, and gentamicin were used. For the Gram-positive bacteria, ampicillin and vancomycin were selected. The antibiotic susceptibility profile of Gram-negative and Grampositive bacteria has been already described by (Dias et al., 2016) and is provided in supplementary materials (Table A1).

\subsubsection{Antiproliferative activity}

The lyophilized hydromethanolic extracts and the infusions were redissolved in water to obtain stock solutions of $4 \mathrm{mg} / \mathrm{mL}$, and then submitted to further dilutions. Four human tumor cell lines were tested: MCF-7 (breast adenocarcinoma), NCI-H460 (non-small cell lung cancer), HeLa (cervical carcinoma), and HepG2 (hepatocellular carcinoma) from DSMZ (Leibniz-Institut DSMZ-Deutsche Sammlung von Mikroorganismen und Zellkulturen $\mathrm{GmbH}$ ). Sulforhodamine B assay was performed according to a procedure previously described by the authors (Barros et al., 2013).

Each of the cell lines were plated in a 96-well plate, at an appropriate density $\left(1.0 \times 10^{4}\right.$ cells/well $)$ and allowed to attach for $24 \mathrm{~h}$. The cells were then incubated in the presence of different extract concentrations during $48 \mathrm{~h}$. Afterwards, cold trichloroacetic acid (TCA $10 \%, 100 \mu \mathrm{L}$ ) was added in order to bind the adherent cells and further incubated for $60 \mathrm{~min}$ at $4{ }^{\circ} \mathrm{C}$. After the incubation period, the plates were washed with deionized water, dried, sulforhodamine B solution (SRB $0.1 \%$ in $1 \%$ acetic acid, $100 \mu \mathrm{L}$ ) was incorporated to each plate well, and incubated for $30 \mathrm{~min}$ at room temperature. The plates were washed with acetic acid $(1 \%)$ in order to remove the unbound SRB and air dried, the bounded SRB was solubilised with Tris $(10 \mathrm{mM}, 200 \mu \mathrm{L})$ and the absorbance was measured at $540 \mathrm{~nm}$ using an ELX800 microplate reader (Bio-Tek Instruments, Inc.; Winooski, VT, USA) (Guimarães et al., 2013).

For evaluation of the hepatotoxicity in non-tumor cells, a cell culture (named as PLP2) was prepared from a freshly harvested porcine liver obtained from a local slaughterhouse, according to a procedure established by the authors (Abreu et al., 2011). The liver tissues were rinsed in Hank's balanced salt solution containing penicillin (100 U/ $\mathrm{mL})$ and streptomycin $(100 \mu \mathrm{g} / \mathrm{mL})$, and divided into $1 \times 1 \mathrm{~mm}^{3}$ explants. A few of these explants were transferred to tissue flasks $\left(25 \mathrm{~cm}^{2}\right)$ containing DMEM medium supplemented with fetal bovine serum (FBS, $10 \%)$, nonessential amino acids $(2 \mathrm{mM})$, penicillin $(100 \mathrm{U} / \mathrm{mL})$, and streptomycin $(100 \mathrm{mg} / \mathrm{mL})$ and incubated at $37^{\circ} \mathrm{C}$ with a humidified atmosphere $\left(5 \% \mathrm{CO}_{2}\right)$. The medium was changed every two days and the cell cultivation was continuously monitored using a phase contrast microscope. When confluence was reached, the cells were sub-cultured and plated in 96-well plate (density of $1.0 \times 10^{4}$ cells/well) containing DMEM medium supplemented with FBS $(10 \%)$, penicillin $(100 \mathrm{U} / \mathrm{mL})$, and streptomycin $(100 \mu \mathrm{g} / \mathrm{mL})$. Ellipticine was used as positive control and the results were expressed in $\mathrm{GI}_{50}$ values (concentration that inhibited $50 \%$ of the net cell growth).

\subsection{Statistical analysis}

Three samples were used for each species and all the assays were carried out in triplicate. The results were expressed as mean values and standard deviation (SD) and analysed using one-way analysis of variance (ANOVA) followed by Tukey's HSD Test with $p=0.05$. When necessary, a Student's $t$-test was used to determine the significant difference between two different samples, with $p=0.05$. These analyses were carried out using IBM SPSS Statistics for Windows, Version 23.0. (IBM Corp., Armonk, NY, USA).

\section{Results and discussion}

\subsection{Individual phenolic profile of the hydromethanolic extracts and} infusions of the flower samples

The extraction yields obtained for the hydromethanolic extract were, $47 \%$ for dahlia, $39 \%$ for rose, $25 \%$ for calendula, and $24 \%$ for centaurea, while the infusion presented the following extraction yields $37 \%$ for dahlia, $34 \%$ for rose, $27 \%$ for calendula, and $22 \%$ for centaurea. Dahlia hydromethanolic extract and infusions showed the most promising yield.

Tables 1-4 presents the compounds characteristic separated using HPLC methodology described above (retention time, $\lambda_{\max }$ in the visible region, mass spectral data), tentative identification and quantification of the phenolic compounds present in the hydromethanolic extracts and infusions prepared from dahlia, rose, centaurea, and calendula petals. 


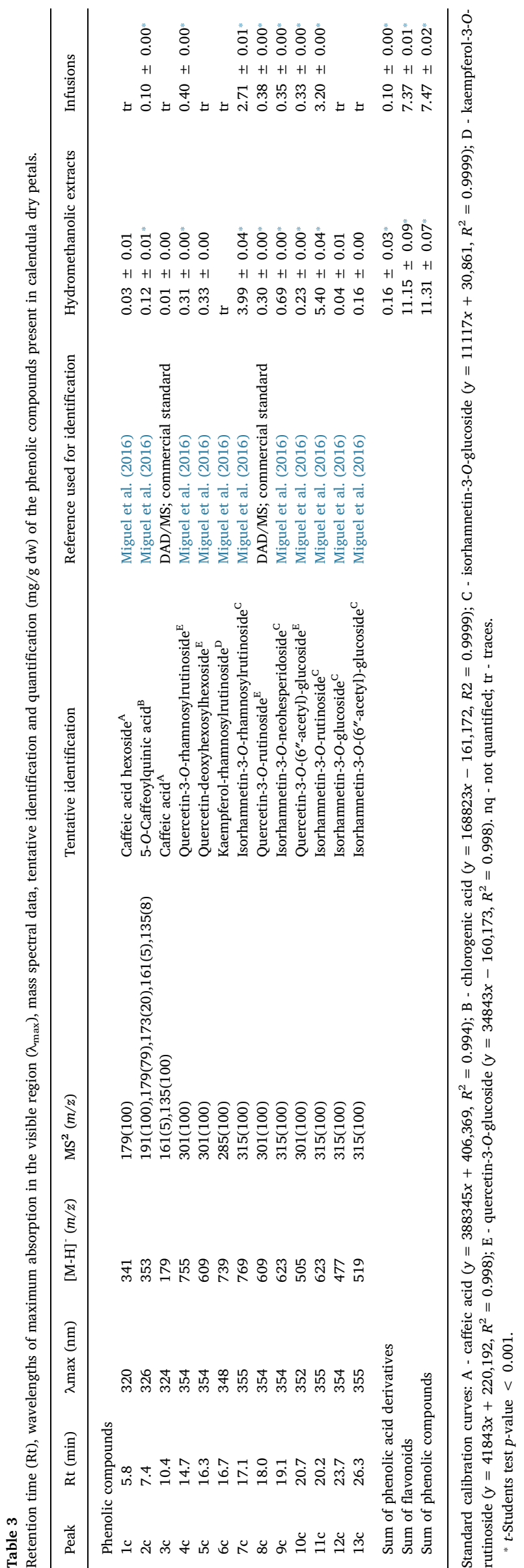

Exemplificative phenolic profiles of all the plants are shown in Fig. A1 in supplementary material. One phenolic acid derivative (chlorogenic acid), twenty flavonoids (eryodictiol, kaempferol, quercetin, apigenin, naringenin, hesperetin, butein, and isoliquiritigenin glycoside derivatives) and two unknown compounds were detected in dahlia samples. Rose petals showed twelve flavonoids, all of them derived from kaempferol and quercetin, and did not reveal any phenolic acid derivative. Three caffeic acid derivatives and ten flavonoids (kaempferol, quercetin, and isorhamnetin glycoside derivatives) were identified in calendula samples. Finally, centaurea samples presented five phenolic acid derivatives (derived from caffeic and $p$-coumaric acids), nine flavonoids (quercetin, kaempferol, apigenin, luteolin, and taxifolin glycoside derivatives) and one unknown compound. Due to the complexity of the discussion, letters were attributed to the peak numbers to identify the plant in which they were found: dahlia (d), rose (r), calendula (c), and centaurea (ce). Table A2 in supplementary material shows the main compounds identified in each sample and type of extract.

\subsubsection{Flavonoids}

3.1.1.1. Flavonols. Quercetin derivatives were detected in the four flower samples. Quercetin-3-O-glucoside (peak 3r) and quercetin-3-Orutinoside (peaks $8 \mathrm{c}$ and $12 \mathrm{~d}$ ) were identified according to their UV spectra, elution order, and fragmentation pattern in comparison to the commercial standard. Compounds $3 \mathrm{r}$ and $8 \mathrm{c}$ were previously identified in rose fruits by Guimarães et al. (2013), and in calendula flowers by Miguel et al. (2016), respectively. Peaks 4c and 10c were identified as quercetin-3-O-rhamnosylrutinoside and quercetin-3-O-(6"-acetyl)glucoside, respectively, which were also previously reported in $C$. officinalis (Miguel et al., 2016). Peak 12ce corresponded to the same compound as peak 10c. Peak 7ce ([M-H $]^{-}$at $m / z$ 667) with three $\mathrm{MS}^{2}$ fragments at $m / z 505$ ( $-162 \mathrm{u}$, loss of a hexosyl moiety), $\mathrm{m} / \mathrm{z} 463$ ( $-42 \mathrm{u}$, loss of an acetyl moiety), and $m / z 301(-162 \mathrm{u}$, loss of a hexosyl moiety) was tentatively identified as quercetin-hexosideacetylhexoside. Peaks $1 \mathrm{r}$ and $5 \mathrm{r}$ were tentatively assigned as quercetin-glucuronide and quercetin-pentoside, respectively, being also previously reported by Guimarães et al. (2013) in $R$. canina fruits. Peak $2 r$ presented the same pseudomolecular ion and fragmentation pattern as peak $3 \mathrm{r}$ (quercetin-3-O-glucoside), but a lower retention time, therefore it was tentatively assigned as a quercetin-hexoside. Similarly, peak $5 \mathrm{c}$ showed the same spectral characteristics as peak 8c (quercetin-3-O-rutinoside), but different retention time so it could not be identified as the pattern, being for that manner tentatively identified as a quercetindeoxyhexosylhexoside. Peak 11r ([M-H $]^{-}$at $m / z$ 609) also presented the same pseudomolecular ion as $8 \mathrm{c}$, but different UV spectra, fragmentation pattern and retention time. The observation in its $\mathrm{MS}^{2}$ spectrum of a product ion at $m / z 463$, from the loss of $146 \mathrm{u}$ and the UV maximum at $314 \mathrm{~nm}$, as well as its late elution, were coherent with the presence of a coumaroyl residue. Therefore, this molecule was tentatively assigned as quercetin-( $p$-coumaroyl)hexoside.

Kaempferol derivatives were also observed in the four studied flowers, being especially relevant in the rose sample. Peaks $4 \mathrm{r}$ and $7 \mathrm{r}$ were identified according to their UV spectra, elution order, fragmentation pattern, and commercial standards, as kaempferol-3-O-rutinoside and kaempferol-3-O-glucoside, respectively. The remaining compounds detected in rose flowers (i.e., peaks $6 r, 8 r, 9 r, 10 r$, and 12r) were assigned following similar reasoning as for quercetin derivatives. Dahlia samples presented two kaempferol derivatives (peaks 9d and 19d) with pseudomolecular ions $[\mathrm{M}-\mathrm{H}]^{-}$at $m / z 771$ and $m / z 563$, both releasing a unique $\mathrm{MS}^{2}$ fragment at $m / z 285$, being associated to kaempferolpentosyl-rhamnosyl-hexoside and kaempferol-pentosyl-rhamnoside, respectively. Centaurea and calendula samples presented one kaempferol derivative each (peaks 14ce and 6c) that were tentatively identified according to their mass spectral characteristics as kaempferolacetylhexoside and kaempferol-rhamnosyl-rutinoside, respectively. This latter compound has already been reported in $C$. officinalis flowers 
Table 4

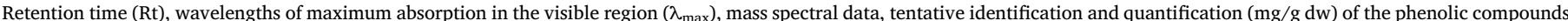
present in centaurea dry petals.

\begin{tabular}{|c|c|c|c|c|c|c|c|c|}
\hline Peak & Rt (min) & $\lambda \max (\mathrm{nm})$ & $\begin{array}{l}{[\mathrm{M}-\mathrm{H}]^{-}} \\
(\mathrm{m} / \mathrm{z})\end{array}$ & $\operatorname{MS}^{2}(m / z)$ & Tentative identification & $\begin{array}{l}\text { Reference used for } \\
\text { identification }\end{array}$ & $\begin{array}{l}\text { Hydromethanolic } \\
\text { extracts }\end{array}$ & Infusions \\
\hline \multicolumn{9}{|c|}{ Phenolic compounds } \\
\hline $1 c e$ & 5.2 & $294,320 \mathrm{sh}$ & 627 & 465(100), 303(3), 285(3) & Taxifolin derivatives $^{\mathrm{E}}$ & DAD/MS & $0.93 \pm 0.02$ & $0.31 \pm 0.00^{*}$ \\
\hline 2ce & 5.7 & 263 & 341 & 179(100), 161(1), 135(1) & Caffeic acid hexoside $^{B}$ & Miguel et al. (2016) & $0.25 \pm 0.01$ & $\operatorname{tr}$ \\
\hline 3ce & 7.3 & 326 & 353 & $\begin{array}{l}\text { 191(100), 179(80), } \\
173(24), 161(5), 135(10)\end{array}$ & cis-5-O-Caffeoylquinic acid ${ }^{\mathrm{C}}$ & $\begin{array}{l}\text { DAD/MS; Barros, Dueñas, } \\
\text { Carvalho, et al. (2012) }\end{array}$ & $1.50 \pm 0.18^{*}$ & $0.17 \pm 0.01^{*}$ \\
\hline 4ce & 7.4 & 326 & 353 & $\begin{array}{l}\text { 191(100), 179(80), } \\
\text { 173(42), 161(5), 135(12) }\end{array}$ & $\begin{array}{l}\text { trans-5-O-Caffeoylquinic } \\
\operatorname{acid}^{\mathrm{C}}\end{array}$ & $\begin{array}{l}\text { DAD/MS; commercial } \\
\text { standard }\end{array}$ & $1.40 \pm 0.06^{*}$ & $0.24 \pm 0.02$ \\
\hline $5 c e$ & 7.8 & 346 & 325 & $163(100)$ & $p$-Coumaric hexoside ${ }^{\mathrm{F}}$ & $\begin{array}{l}\text { Barros, Dueñas, Pinela et al. } \\
\text { (2012) }\end{array}$ & $0.93 \pm 0.01^{*}$ & $0.09 \pm 0.01^{*}$ \\
\hline $6 c e$ & 8.2 & 312 & 325 & $163(100)$ & $p$-Coumaric hexoside $\mathrm{e}^{\mathrm{F}}$ & $\begin{array}{l}\text { Barros, Dueñas, Pinela, et al. } \\
\text { (2012) }\end{array}$ & $0.44 \pm 0.06^{*}$ & $0.04 \pm 0.00^{*}$ \\
\hline 7ce & 13.0 & 350 & 667 & $\begin{array}{l}\text { 505(100), 463(43), } \\
301(14)\end{array}$ & $\begin{array}{l}\text { Quercetin-hexoside- } \\
\text { acetylhexoside }^{\mathrm{E}}\end{array}$ & $\begin{array}{l}\text { Barros, Dueñas, Carvalho, } \\
\text { et al. (2012) }\end{array}$ & $0.78 \pm 0.00^{*}$ & $0.26 \pm 0.00$ \\
\hline $8 c e$ & 13.4 & $274,317 \mathrm{sh}$ & 627 & 465(100), 303(3), 285(4) & Taxifolin derivatives ${ }^{\mathrm{E}}$ & $\mathrm{DAD} / \mathrm{MS}$ & $1.08 \pm 0.04$ & $0.28 \pm 0.01^{*}$ \\
\hline $9 c e$ & 13.7 & $276,316 \mathrm{sh}$ & 627 & $465(100), 303(1), 285(3)$ & Taxifolin derivatives $^{\mathrm{E}}$ & $\mathrm{DAD} / \mathrm{MS}$ & $1.11 \pm 0.12$ & $0.25 \pm 0.01^{*}$ \\
\hline $10 \mathrm{ce}$ & 17.8 & 320 & 649 & 473(100), 269(8) & $\begin{array}{l}\text { Apigenin-glucuronide- } \\
\text { acetylhexoside }^{\mathrm{A}}\end{array}$ & $\mathrm{DAD} / \mathrm{MS}$ & $1.25 \pm 0.00^{*}$ & $0.46 \pm 0.01 *$ \\
\hline 11ce & 18.9 & 346 & 461 & $285(100)$ & Luteolin-glucuronide $^{\mathrm{E}}$ & Miguel et al. (2016) & $0.83 \pm 0.01^{*}$ & $0.26 \pm 0.00^{*}$ \\
\hline 12ce & 20.4 & 353 & 505 & 463(23), 301(100) & $\begin{array}{l}\text { Quercetin-3-O-(6"-acetyl)- } \\
\text { glucoside }^{\mathrm{E}}\end{array}$ & $\begin{array}{l}\text { Barros, Dueñas, Carvalho, } \\
\text { et al. (2012) }\end{array}$ & $0.83 \pm 0.01^{*}$ & $0.25 \pm 0.00^{*}$ \\
\hline 13ce & 23.9 & 337 & 445 & $269(100)$ & Apigenin-glucuronide $^{\mathrm{A}}$ & Guimarães et al. (2013) & $12.22 \pm 0.09^{*}$ & $1.52 \pm 0.13^{*}$ \\
\hline $14 \mathrm{ce}$ & 24.8 & 330 & 489 & $285(100)$ & $\begin{array}{l}\text { Kaempferol- } \\
\text { acetylhexoside }^{\mathrm{D}}\end{array}$ & $\begin{array}{l}\text { Barros, Dueñas, Carvalho, } \\
\text { et al. (2012) }\end{array}$ & $\operatorname{tr}$ & $\operatorname{tr}$ \\
\hline \multicolumn{7}{|c|}{ Sum of phenolic acid derivatives } & $4.52 \pm 0.17^{*}$ & $0.55 \pm 0.02$ \\
\hline \multicolumn{7}{|c|}{ Sum of flavonoids } & $19.03 \pm 0.06^{*}$ & $3.59 \pm 0.03^{*}$ \\
\hline \multicolumn{7}{|c|}{ Sum of phenolic compounds } & $23.55 \pm 0.11^{*}$ & $4.14 \pm 0.05^{*}$ \\
\hline
\end{tabular}

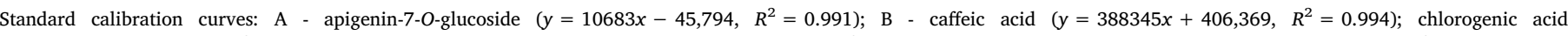

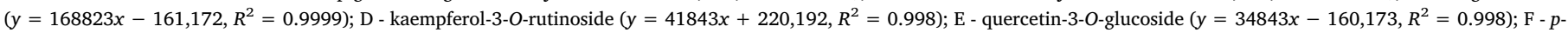
coumaric acid $\left(y=301950 x+6966.7, R^{2}=0.9999\right)$. nq - not quantified; $t r$ - traces.

${ }^{*} t$-Students test $p$-value $<0.001$.

by our group (Miguel et al., 2016).

Isorhamnetin derivatives were only detected in the calendula samples (peaks 7c, 9c, 11c, 12c, and 13c), being identified as isorhametin-3$O$-rhamnosylrutinoside ([M-H $]^{-}$at $m / z$ 769), isorhametin-3-O-neohesperidoside $\left([\mathrm{M}-\mathrm{H}]^{-}\right.$at $\left.m / z 623\right)$, isorhametin-3-O-rutinoside $\left([\mathrm{M}-\mathrm{H}]^{-}\right.$ at $m / z 623)$, isorhametin-3-O-glucoside ([M-H $]^{-}$at $\left.m / z 477\right)$ and isorhametin-3-O-(6"-acetyl)-glucoside ([M-H $]^{-}$at $\left.m / z 519\right)$, respectively, all of them previously reported in $C$. officinalis flowers by Miguel et al. (2016).

3.1.1.2. Flavones. Peaks $13 \mathrm{~d}\left([\mathrm{M}-\mathrm{H}]^{-}\right.$at $\left.m / z 431\right)$ and $13 c e\left([\mathrm{M}-\mathrm{H}]^{-}\right.$ at $m / z 445$ ), presented a unique $\mathrm{MS}^{2}$ fragment at $m / z 269$ (associated to apigenin), corresponding to the loss of hexosyl $(-162 \mathrm{u})$ and glucuronyl $(-176 \mathrm{u})$ moieties, so that they were tentatively identified as apigenin-hexoside and apigenin-glucuronide, respectively. An identity of peak $13 \mathrm{~d}$ as apigenin-7-O-glucoside was discarded by comparison with a standard. Peak 10ce ([M-H] ${ }^{-}$at $m / z$ 649) released two $\mathrm{MS}^{2}$ fragments at $m / z 473$ (176 u, loss of a glucuronyl moiety) and $m / z 269(162+42 \mathrm{u}$, further loss of an acetylhexosyl residue), being tentatively identified as an apigeninglucuronide-acetylhexoside. Peak 11ce, with a pseudomolecular ion $[\mathrm{M}-\mathrm{H}]^{-}$at $m / z 461$ releasing a unique $\mathrm{MS}^{2}$ fragment at $m / z 285$ (loss of $176 \mathrm{u}$, corresponding to a glucuronyl moiety), was tentatively identified as a luteolin-glucuronide.

3.1.1.3. Flavanones. They were only detected in dahlia samples. Peaks $1 \mathrm{~d}\left([\mathrm{M}-\mathrm{H}]^{-}\right.$at $\left.m / z 653\right), 3 \mathrm{~d}$ and $4 \mathrm{~d}\left([\mathrm{M}-\mathrm{H}]^{-}\right.$at $\left.m / z 611\right), 6 \mathrm{~d}\left([\mathrm{M}-\mathrm{H}]^{-}\right.$ at $m / z 653), 8 \mathrm{~d}\left([\mathrm{M}-\mathrm{H}]^{-}\right.$at $\left.m / z 595\right)$, and $10 \mathrm{~d}\left([\mathrm{M}-\mathrm{H}]^{-}\right.$at $\left.\left.m / z 449\right]\right)$, presenting characteristic UV spectra with $\lambda_{\max }$ around $274 \mathrm{~nm}$ and an $\mathrm{MS}^{2}$ product ion at $m / z 287$, were associated as eriodictyol derivatives. According to their pseudomolecular ions they were tentatively identified as eriodictyol-acetyldihexoside (1d and 6d), eriodictyoldihexoside (4d), eriodictyol-deoxyhexosyl-hexoside (8d), and eriodictyol-hexoside (10d). Peak $15 \mathrm{~d}\left([\mathrm{M}-\mathrm{H}]^{-}\right.$at $\mathrm{m} / \mathrm{z}$ 433) was identified as naringenin-3-O-glucoside based on its LC-MS characteristics in comparison with data available in our compound library. Peak14d $\left([\mathrm{M}-\mathrm{H}]^{-}\right.$at $m / z$ 637) showing an $\mathrm{MS}^{2}$ fragmentation pattern at $m / z 475$ ([M-H-162 $]^{-}$) and 271 (further loss of $162+42 \mathrm{u}$ ) was tentatively assigned as naringenin-hexoside-acetylhexoside. Peak $17 \mathrm{~d}\left([\mathrm{M}-\mathrm{H}]^{-}\right.$at $\left.m / z 579\right)$ presented a unique $\mathrm{MS}^{2}$ fragment at $m / z 301$ ( $-132-146 \mathrm{u}$, loss of pentosyl rhamnosyl moieties) was tentatively identified as hesperetin-pentosyl-rhamnoside.

Peaks $5 d$ and $7 d$ presented a pseudomolecular ion $[\mathrm{M}-\mathrm{H}]^{-}$at $m / z$ 465 that is coherent with a pentahydroxyflavanone structure, also the UV spectra presented by this compounds at $\lambda_{\max } 270 \mathrm{~nm}$ with a shoulder at $320 \mathrm{~nm}$ is also characteristic with dihydroflavonoids, being tentatively assigned as pentahydroxyflavanone-dihexoside (5d) and pentahydroxyflavanone-acetylhexoside-hexoside (7d).

3.1.1.4. Dihydroflavonols. Peaks 1ce, 8ce, and 9ce, all of them showing the same pseudomolecular ion $[\mathrm{M}-\mathrm{H}]^{-}$at $\mathrm{m} / \mathrm{z} 627$, detected in centaurea samples, were associated to taxifolin (i.e., dihydroquercetin) with hexose and caffeic acid residues (both with $162 \mathrm{mu}$ ). This could be explained by the characteristic UV spectra shape with a shoulder over $320 \mathrm{~nm}$ and also by the low abundance of the $m / z$ 303 fragment. The $m / z 465$ fragment would correspond to the loss of one hexoside moiety $\left([\mathrm{M}-162]^{-}\right)$, whereas the loss of the caffeic moiety could be justify the low abundance of the $m / z 303$ fragment.

3.1.1.5. Chalcones. Seven compounds detected in dahlia samples were identified as chalcones.

Peaks 11d and 16d presented an aglycone with $\mathrm{m} / \mathrm{z}$ at 255 that fits both the flavanone liquiritigenin and its corresponding chalcone isoliquiritigenin. However, the flavanone nature was discarded based on their UV spectra showing $\lambda_{\max }$ around $360 \mathrm{~nm}$, characteristic of chalcones, as also checked by comparison with a commercial standard of 
isoliquiritigenin. According to their pseudomolecular ions and $\mathrm{MS}^{2}$ fragmentation patterns, they were tentatively identified as isoliquiritigenin-dihexoside and isoliquiritigenin-hexoside-acetylhexoside.

Peaks 18d, 20d, and 21d showed similar spectra shapes as the previous ones with $\lambda_{\max }$ around $370-380 \mathrm{~nm}$, and a common $\mathrm{MS}^{2}$ product ion at $m / z$ at 271 that matched the chalcone butein. The pseudomolecular ion $\left([\mathrm{M}-\mathrm{H}]^{-}\right.$at $\left.m / z 433\right)$ of peak $18 \mathrm{~d}$ was coherent with butein hexosides, being the first of them (the majority one) assigned as coreopsin (butein-4'-glucoside), described as a main flavonoid in other species of the Asteraceae family, such as Coreopsis tinctoria (Chen et al., 2016a; Yang et al., 2016). Peak 20d, possessing a molecular weight $42 \mathrm{u}$ higher that peak 18d, was tentatively assigned as acetylcoreopsin, also reported in Coreopsis tinctoria (Yang et al., 2016). Peak 23d should correspond to a coreopsin derivative, although no definite identity could be assigned to it.

The most abundant flavonoids in dahlia (except dahlia's infusions), rose, calendula, and centaurea were naringenin-3-O-glucoside, quercetin-3-O-glucoside, isorhamnetin-3-O-rutinoside, and apigenin-glucuronide, respectively. Calendula hydromethanolic extracts and infusions presented the highest concentration of flavonoids (11.15 and $7.37 \mathrm{mg} / \mathrm{g}$, respectively) and total phenolic compounds (11.31 and $7.47 \mathrm{mg} / \mathrm{g}$, respectively) from all the studied samples. It also showed higher concentration of these compounds when compared to the ones reported by Miguel et al. (2016) in C. officinalis samples. This difference could be related to the type of treatment that were given to the sample (e.g. drying process), as well as the geographic origin of the samples.

\subsubsection{Phenolic acids}

Phenolic acid derivatives represent the second major class found in the four flower samples, but in rose flowers this kind of compounds were not detected. Caffeic acid (peaks 3c) and 5-O-caffeoylquinic acid (chlorogenic acid; peaks 2d, 2c, and 4ce) were positively identified according to their retention, mass, and UV-vis characteristics by comparison with commercial standards. Peak 3ce was assigned as the cis form of 5-O-caffeoylquinic acid, since the cis hydroxycinnamoyl derivatives would be expected to elute before the corresponding trans ones (Barros, Dueñas, Carvalho, et al., 2012). Peaks 1c and 2ce ([M-H] ${ }^{-}$at $\mathrm{m} / \mathrm{z} 341$ ) were tentatively identified as caffeic acid hexoside. The presence of caffeic acid hexoside and 5-O-caffeoylquinic acid was already reported in C. officinalis by our group (Miguel et al., 2016). Finally, peaks $5 c e$ and $6 c e$ were tentatively identified as $p$-coumaric hexoside based on their pseudomolecular ion ([M-H $]^{-}$at $\left.m / z 325\right)$ and the $\mathrm{MS}^{2}$ fragment at $m / z 163$ ([coumaric acid-H] $^{-},-162 \mathrm{u}$, loss of a hexosyl moiety). The observation of two compounds could be explained by a different location of the sugar residue on the coumaric acid or the existence of cis/trans isomers.

The hydromethanolic extract from centaurea samples presented the highest concentration in phenolic acids; while for the infusions the highest concentration of phenolic acids was found in centaurea sample. Chlorogenic acid was the most abundant phenolic acid present in all samples, which may be very interesting since this compound has been correlated with various biological effects, including antioxidant, antiobesity, antiapoptosis, and antitumor activities (Kamiyama, Moon, Jang, \& Shibamoto, 2015; Rakshit et al., 2010).

\subsection{Bioactivities of the hydromethanolic extracts and infusions of the flower samples}

Data regarding antioxidant, antiproliferative, and antibacterial activities of the hydromethanolic extracts and infusions of the four studied flowers are presented in Table 5. The hydromethanolic extracts and the infusions of rose petals were able to inhibit lipid peroxidation and to prevent oxidative damage, as well as, promote free radicals scavenging according to the results obtained for the DPPH radical scavenging assay ( 0.18 and $0.82 \mathrm{mg} / \mathrm{mL}$, respectively), reducing power (1.29 and $0.64 \mathrm{mg} / \mathrm{mL}$, respectively) and $\beta$-carotene bleaching inhibition ( 0.38 and $1.12 \mathrm{mg} / \mathrm{mL}$, respectively) These results were in accordance with those obtained by Barros et al. (2011) for petals of Rosa canina L. Researches revealed that phytochemicals such as anthocyanins, flavonoids, phenolic acids, alkaloids, and glycosides in edible flowers exerted high anti-oxidant activities (Lu, Li, \& Yin, 2016).

The hydromethanolic extracts of calendula showed lower $\mathrm{EC}_{50}$ values (higher antioxidant activity) in the DPPH and $\beta$-carotene bleaching inhibition assays than the ones reported by Miguel et al. (2016). These differences may be related to the presence of total flavonoids present in the samples as described by Lu et al., 2016.

Regarding antiproliferative activity, not all the samples studied inhibit the growth of the studied tumor cell lines. Dahlia hydromethanolic extracts and infusion gave the lowest $\mathrm{GI}_{50}$ values against HeLa $(223.65 \mu \mathrm{g} / \mathrm{mL})$ and MCF-7 $(361.99 \mu \mathrm{g} / \mathrm{mL}, 303.27 \mu \mathrm{g} / \mathrm{mL}$ respectively) cell lines. The presence of flavanones only detected in dahlia samples, may have contributed to antiproliferative activity against more cell line (Manthey and Guthrie, 2002). Rose hydromethanolic extract also presented the capacity to inhibit the growth of tumor cell lines, such cervical and hepatocellular carcinoma. Similar results were also described by Nadpal et al. (2016) for rose sample using a cervical carcinoma cell line $(308.5 \mu \mathrm{g} / \mathrm{mL})$. Centaurea and calendula hydromethanolic extracts and infusions showed hardly or no antiproliferative activity, with $\mathrm{GI}_{50}$ values higher than $400 \mu \mathrm{g} / \mathrm{mL}$ in all the tested cells. None of the extracts or infusions presented hepatoxicity toward the non-tumor liver primary culture (PLP2).

The obtained data for antimicrobial activity were presented in Table 5. Our results showed that samples were active against all the microorganisms used, however in most cases, the samples were found to be more active against Gram-positive bacteria with MICs ranging from 0.625 to $10 \mathrm{mg} / \mathrm{mL}$. These results were in accordance with results presented by Nowak et al. (2014). For Gram-positive bacteria, the infusions of rose samples showed the best results for Staphylococcus aureus $(0.625 \mathrm{mg} / \mathrm{mL})$, MRSA $(0.625 \mathrm{mg} / \mathrm{mL})$, and MSSA $(1.25 \mathrm{mg} / \mathrm{mL})$. The hydromethanolic extracts of rose sample also showed the best antibacterial activity against Gram-negative bacteria, E. coli and Morganella morganii $(1.25 \mathrm{mg} / \mathrm{mL}$, for both). To obtain this beneficial effect with the consumption of this plant, and considering the mentioned MICs, a portion of $3.9 \mathrm{mg}$ of rose plant $/ \mathrm{mL}$ (e.g. $0.78 \mathrm{~g}$ per cup of infusion) would be necessary. For the remaining plants the necessary portions would be $2.4,5$ and $4.8 \mathrm{mg}$ of dahlia, calendula and centaurea, respectively per mL. Extended-spectrum beta-lactamase-producing (ESBL 2) Escherichia coli was not affected by any infusions studied.

Overall, this is an innovative study on the phenolic profile, antioxidant, antiproliferative, and antibacterial activities of dahlia, rose and centaurea petals. Meanwhile, for calendula petals the mentioned bioactivities were previously reported Miguel et al. (2016). Flavonoids were the predominant compounds in all the studied samples, although each of them presented different phenolic profiles, both in terms of phenolic families and contents. The highest concentration of total phenolic compounds was found in calendula, with relevant amounts of isorhamnetin derivatives. The hydromethanolic extracts and infusions of rose petals showed the greatest antioxidant activity, which could be due to the presence of quercetin and kaempferol derivatives.

Flavonoids are also considered safe compounds with low potential to induce organic toxicity (Middleton Jr. et al., 2000). However, they can exhibit prooxidant activity explaining some mutagenic and cytotoxic effect (Galati \& O'Brien, 2004). The prooxidant and antioxidant properties of flavonoids such as quercetin and kaempferol derivatives, depend on the environment in which they are inserted as also their chemical structure and concentration (Carocho \& Ferreira, 2013).

The hydromethanolic extracts of rose petals showed the best results for the antibacterial activity, and dahlia hydromethanolic extracts for the antiproliferative activity against almost all the tumor cell lines tested, with the exception of NCI-H460. Antiproliferative and antibacterial activities were also highly related with phenolic compounds.

These results support the potential of edible flowers as sources of 
Table 5

Antioxidant, antiproliferative, hepatotoxic and antibacterial activities of hydromethanolic extracts and infusions of the studied flowers (mean \pm SD).

\begin{tabular}{|c|c|c|c|c|c|c|c|c|}
\hline & \multicolumn{4}{|c|}{ Hydromethanolic extracts } & \multicolumn{4}{|l|}{ Infusions } \\
\hline & Dahlia & Rose & Calendula & Centaurea & Dahlia & Rose & Calendula & Centaurea \\
\hline \multicolumn{9}{|l|}{$\begin{array}{l}\text { Antioxidant activity } \mathrm{EC}_{50} \\
\text { values }(\mathrm{mg} / \mathrm{mL})^{\mathrm{A}}\end{array}$} \\
\hline DPPH scavenging activity & $0.63 \pm 0.01^{\mathrm{c}}$ & $0.18 \pm 0.02^{\mathrm{d}}$ & $1.37 \pm 0.08^{\mathrm{a}}$ & $0.83 \pm 0.03^{\mathrm{b}}$ & $1.17 \pm 0.05^{\mathrm{c}}$ & $0.82 \pm 0.01^{\mathrm{d}}$ & $16.71 \pm 0.29^{\mathrm{a}}$ & $10.78 \pm 0.26^{\mathrm{b}}$ \\
\hline Reducing power & $1.33 \pm 0.07^{\mathrm{b}}$ & $1.29 \pm 0.09^{\mathrm{b}}$ & $7.96 \pm 0.08^{\mathrm{a}}$ & $8.14 \pm 0.18^{\mathrm{a}}$ & $0.799 \pm 0.001^{\mathrm{d}}$ & $0.64 \pm 0.01^{\mathrm{c}}$ & $10.19 \pm 0.12^{\mathrm{a}}$ & $5.10 \pm 0.03^{b}$ \\
\hline $\begin{array}{l}\beta \text {-carotene bleaching } \\
\text { inhibition }\end{array}$ & $0.48 \pm 0.02^{\mathrm{bc}}$ & $0.38 \pm 0.03^{c}$ & $0.66 \pm 0.08^{b}$ & $1.17 \pm 0.01^{\mathrm{a}}$ & $2.01 \pm 0.07^{c}$ & $1.12 \pm 0.04^{\mathrm{d}}$ & $8.50 \pm 0.08^{\mathrm{a}}$ & $8.06 \pm 0.30^{b}$ \\
\hline \multicolumn{9}{|l|}{ Antiproliferative activity } \\
\hline MCF-7 (breast carcinoma) & $361.99 \pm 28.83$ & $>400$ & $>400$ & $>400$ & $303.27 \pm 26.13^{\mathrm{b}}$ & $377.09 \pm 32.09^{\mathrm{a}}$ & $>400$ & $>400$ \\
\hline $\begin{array}{l}\text { NCI-H460 (non-small cell } \\
\text { lung carcinoma) }\end{array}$ & $>400$ & $>400$ & $>400$ & $>400$ & $>400$ & $>400$ & $>400$ & $>400$ \\
\hline $\begin{array}{l}\text { HeLa (cervical } \\
\text { carcinoma) }\end{array}$ & $223.65 \pm 2.78^{\mathrm{b}}$ & $308.45 \pm 17.13^{\mathrm{a}}$ & $>400$ & $>400$ & $>400$ & $>400$ & $>400$ & $>400$ \\
\hline $\begin{array}{l}\text { HepG2 (hepatocellular } \\
\text { carcinoma) }\end{array}$ & $339.15 \pm 15.14^{\mathrm{a}}$ & $296.82 \pm 23.71^{\mathrm{b}}$ & $>400$ & $>400$ & $>400$ & $315.33 \pm 19.28$ & $>400$ & $>400$ \\
\hline \multicolumn{9}{|l|}{$\begin{array}{l}\text { Hepatotoxicity } \mathrm{GI}_{50} \text { values } \\
(\mu \mathrm{g} / \mathrm{mL})^{\mathrm{B}}\end{array}$} \\
\hline PLP2 & $>400$ & $>400$ & $>400$ & $>400$ & $>400$ & $>400$ & $>400$ & $>400$ \\
\hline \multicolumn{9}{|l|}{$\begin{array}{l}\text { Antibacterial activity MIC } \\
\text { values }(\mathrm{mg} / \mathrm{mL})\end{array}$} \\
\hline \multicolumn{9}{|l|}{ Gram-negative bacteria } \\
\hline Acinetobacter baumannii & 5 & 2.5 & 10 & 5 & 10 & 2.5 & $>20$ & $>20$ \\
\hline Escherichia coli ESBL 1 & 5 & 5 & 10 & 5 & 10 & 10 & 10 & 20 \\
\hline Escherichia coli ESBL 2 & 5 & 1.25 & 5 & 5 & - & - & - & - \\
\hline Escherichia coli & 2.5 & 5 & 20 & 20 & 10 & 5 & 20 & 20 \\
\hline Klebsiella pneumoniae & 5 & 2.5 & 5 & 10 & $>20$ & 10 & $>20$ & $>20$ \\
\hline $\begin{array}{l}\text { Klebsiella pneumoniae } \\
\text { ESBL }\end{array}$ & 5 & 2.5 & 10 & 5 & $>20$ & 10 & $>20$ & $>20$ \\
\hline Morganella morganii & 2.5 & 1.25 & 20 & 10 & 2.5 & 1.25 & 20 & 20 \\
\hline Pseudomonas aeruginosa & $>20$ & 2.5 & 5 & 10 & 20 & 2.5 & $>20$ & 20 \\
\hline \multicolumn{9}{|l|}{ Gram-positive bacteria } \\
\hline Enterococcus faecalis & 2.5 & 2.5 & 5 & 20 & 5 & $>20$ & 20 & $>20$ \\
\hline Listeria monocytogenes & 5 & 10 & 5 & 20 & 5 & $>20$ & 20 & $>20$ \\
\hline Staphylococcus aureus & 2.5 & 1.25 & 10 & 5 & 1.25 & 0.625 & 20 & 5 \\
\hline MRSA & 5 & 1.25 & 5 & 5 & 2.5 & 0.625 & $>20$ & 20 \\
\hline MSSA & 5 & 1.25 & 10 & 10 & 2.5 & 1.25 & 20 & 10 \\
\hline
\end{tabular}

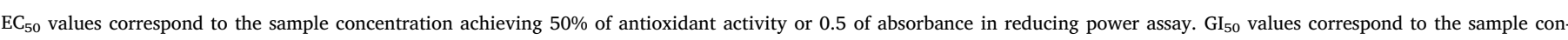

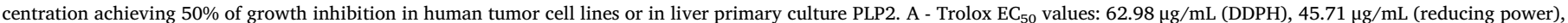

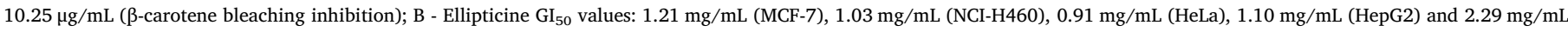

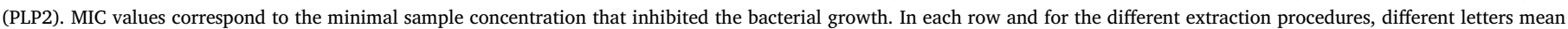
significant differences $(p<0.05)$.

phenolic compounds with bioactive potential, having a high phytochemical interest for the food industry.

\section{Acknowledgements}

The authors are grateful to the Foundation for Science and Technology (FCT, Portugal) and FEDER under Programme PT2020 for financial support to CIMO (UID/AGR/00690/2013), T.C.S.P. Pires (SFRH/BD/129551/2017) grant, L. Barros contract and to the Interreg España-Portugal for financial support through the project 0377_Iberphenol_6_E. The authors are also grateful to Prof. Carlos Aguiar (CIMO) for systematic identification of the studied species.

\section{Appendix A. Supplementary data}

Supplementary data to this article can be found online at https:// doi.org/10.1016/j.foodres.2017.11.014.

\section{References}

Abreu, R. M. V., Ferreira, I. C. F. R., Calhelha, R. C., Lima, R. T., Vasconcelos, M. H. Adega, F., ... Queiroz, M. J. R. P. (2011). Anti-hepatocellular carcinoma activity using human HepG2 cells and hepatotoxicity of 6-substituted methyl 3-aminothieno[3,2-b] pyridine-2-carboxylate derivatives: in vitro evaluation, cell cycle analysis and QSAR studies. European Journal of Medicinal Chemistry, 46, 5800-5806. http://dx.doi.org/ 10.1016/j.ejmech.2011.09.029.

Anantharaju, P. G., Gowda, P. C., Vimalambike, M. G., \& Madhunapantula, S. V. (2016) An overview on the role of dietary phenolics for the treatment of cancers. Nutrition Journal, 15, 99. http://dx.doi.org/10.1186/s12937-016-0217-2.

Barros, L., Carvalho, A. M., \& Ferreira, I. C. F. R. (2011). Exotic fruits as a source of important phytochemicals: Improving the traditional use of Rosa canina fruits in Portugal. Food Research International, 44, 2233-2236. http://dx.doi.org/10.1016/j. foodres.2010.10.005.

Barros, L., Dueñas, M., Ferreira, I. C., Carvalho, A. M., \& Santos-Buelga, C. (2011). Use of HPLC-DAD-ESI/MS to profile phenolic compounds in edible wild greens from Portugal. Food Chemistry, 127(1), 169-173.

Barros, L., Dueñas, M., Carvalho, A. M., Ferreira, I. C. F. R., \& Santos-Buelga, C. (2012). Characterization of phenolic compounds in flowers of wild medicinal plants from Northeastern Portugal. Food and Chemical Toxicology, 50, 1576-1582. http://dx.doi. org/10.1016/j.fct.2012.02.004.

Barros, L., Dueñas, M., Pinela, J., Carvalho, A. M., Buelga, C. S., \& Ferreira, I. C. F. R. (2012). Characterization and quantification of phenolic compounds in four tomato (Lycopersicon esculentum L.) farmers' varieties in Northeastern Portugal homegardens. Plant Foods for Human Nutrition, 67, 229-234. http://dx.doi.org/10.1007/s11130012-0307-z.

Barros, L., Pereira, E., Calhelha, R. C., Dueñas, M., Carvalho, A. M., Santos-Buelga, C., \& Ferreira, I. C. F. R. (2013). Bioactivity and chemical characterization in hydrophilic and lipophilic compounds of Chenopodium ambrosioides L. Journal of Functional Foods, 5, 1732-1740. http://dx.doi.org/10.1016/j.jff.2013.07.019.

Bessada, S. M. F., Barreira, J. C. M., Barros, L., Ferreira, I. C. F. R., \& Oliveira, M. B. P. P. (2016). Phenolic profile and antioxidant activity of Coleostephus myconis (L.) Rchb.f.: An underexploited and highly disseminated species. Industrial Crops and Products, 89, 45-51. http://dx.doi.org/10.1016/j.indcrop.2016.04.065.

Brouillard, R. (1988). Flavonoids and flower colour. In C. Hall (Ed.). The Flavonoids London (pp. 525-538). . http://dx.doi.org/10.1007/978-1-4899-2911-2 13.

Carocho, M., \& Ferreira, I. C. F. R. (2013). A review on antioxidants, prooxidants and 
related controversy: Natural and synthetic compounds, screening and analysis methodologies and future perspectives. Food and Chemical Toxicology. http://dx.doi. org/10.1016/j.fct.2012.09.021.

Chen, L. X., Hu, D. J., Lam, S. C., Ge, L., Wu, D., Zhao, J., ... Li, S. P. (2016a). Comparison of antioxidant activities of different parts from snow chrysanthemum (Coreopsis tinctoria Nutt.) and identification of their natural antioxidants using high performance liquid chromatography coupled with diode array detection and mass sp. Journal of Chromatography A, 1428, 134-142. http://dx.doi.org/10.1016/j.chroma. 2015.10.037.

Demir, N., Yildiz, O., Alpaslan, M., \& Hayaloglu, A. A. (2014). Evaluation of volatiles, phenolic compounds and antioxidant activities of rose hip (Rosa L.) fruits in Turkey. LWT - Food Science and Technology. http://dx.doi.org/10.1016/j.lwt.2013.12.038.

Dias, M. I., Barros, L., Morales, P., Cámara, M., Alves, M.-J., Oliveira, M. B., ... Ferreira, I. C. F. R. (2016). Wild Fragaria vesca L. fruits: A rich source of bioactive phytochemicals. Food \& Function, 4523-4532. http://dx.doi.org/10.1039/c6fo01042c.

Fernandes, L., Casal, S., Pereira, J. A., Saraiva, J. A., \& Ramalhosa, E. (2017). Edible flowers: A review of the nutritional, antioxidant, antimicrobial properties and effects on human health. Journal of Food Composition and Analysis, 60, 38-50. http://dx.doi. org/10.1016/j.jfca.2017.03.017.

Galati, G., \& O'Brien, P. J. (2004). Potential toxicity of flavonoids and other dietary phenolics: Significance for their chemopreventive and anticancer properties. Free Radical Biology and Medicine. http://dx.doi.org/10.1016/j.freeradbiomed.2004.04. 034.

Guimarães, R., Barros, L., Dueñas, M., Carvalho, A. M., Queiroz, M. J. R. P., SantosBuelga, C., \& Ferreira, I. C. F. R. (2013). Characterisation of phenolic compounds in wild fruits from Northeastern Portugal. Food Chemistry, 141, 3721-3730. http://dx doi.org/10.1016/j.foodchem.2013.06.071.

Gutiérrez-Grijalva, P. E., Libna Ambriz-Pére, D., Leyva-López, N., Ignacio Castillo-López, R., \& Basilio Heredia, J. (2016). Review: Dietary phenolic compounds, health benefits and bioaccessibility.

Harbaum, B., Hubbermann, E. M., Wolff, C., Herges, R., Zhu, Z., \& Schwarz, K. (2007) Identification of flavonoids and hydroxycinnamic acids in pak choi varieties (Brassica campestris L. ssp. chinensis var. communis) by HPLC-ESI-MSn and NMR and their quantification by HPLC-DAD. Journal of Agricultural and Food Chemistry, 55, 8251-8260. http://dx.doi.org/10.1021/jf071314.

Hatano, T., Kagawa, H., Yasuhara, T., \& Okuda, T. (1988). Two new flavonoids and other constituents in licorice root: Their relative astringency and radical scavenging effects. Chemical \& Pharmaceutical Bulletin, 36, 2090-2097.

Hvattum, E. (2002). Determination of phenolic compounds in rose hip (Rosa canina) using liquid chromatography coupled to electrospray ionisation tandem mass spectrometry and diode-array detection. Rapid Communications in Mass Spectrometry, 16, 655-662. http://dx.doi.org/10.1002/rcm.622.

Kaisoon, O., Siriamornpun, S., Weerapreeyakul, N., \& Meeso, N. (2011). Phenolic compounds and antioxidant activities of edible flowers from Thailand. Journal of Functional Foods, 3, 88-99. http://dx.doi.org/10.1016/j.jff.2011.03.002.

Kamiyama, M., Moon, J. K., Jang, H. W., \& Shibamoto, T. (2015). Role of degradation products of chlorogenic acid in the antioxidant activity of roasted coffee. Journal of Agricultural and Food Chemistry, 63, 1996-2005. http://dx.doi.org/10.1021/ jf5060563.

Kou, L., Turner, E. R., \& Luo, Y. (2012). Extending the shelf life of edible flowers with controlled release of 1-methylcyclopropene and modified atmosphere packaging. Journal of Food Science, 77. http://dx.doi.org/10.1111/j.1750-3841.2012.02683.x.

Kuete, V., Ango, P. Y., Fotso, G. W., Kapche, G. D. W. F., Dzoyem, J. P., Wouking, A. G., .. Abegaz, B. M. (2011). Antimicrobial activities of the methanol extract and compounds from Artocarpus communis (Moraceae). BMC Complementary and Alternative Medicine, 11, 42. http://dx.doi.org/10.1186/1472-6882-11-42.

Kuete, V., Kamga, J., Sandjo, L. P., Ngameni, B., Poumale, H. M., Ambassa, P., \& Ngadjui, B. T. (2011). Antimicrobial activities of the methanol extract, fractions and compounds from Ficus polita Vahl. (Moraceae). BMC Complementary and Alternative
Medicine, 11, 6. http://dx.doi.org/10.1186/1472-6882-11-6.

Kuś, P. M., Jerković, I., Tuberoso, C. I. G., Marijanović, Z., \& Congiu, F. (2014). Cornflower (Centaurea cyanus L.) honey quality parameters: Chromatographic fingerprints, chemical biomarkers, antioxidant capacity and others. Food Chemistry, 142, 12-18. http://dx.doi.org/10.1016/j.foodchem.2013.07.050.

Lin, L. Z., Mukhopadhyay, S., Robbins, R. J., \& Harnly, J. M. (2007). Identification and quantification of flavonoids of Mexican oregano (Lippia graveolens) by LC-DAD-ESI/ MS analysis. Journal of Food Composition and Analysis, 20, 361-369. http://dx.doi. org/10.1016/j.jfca.2006.09.005.

Lu, B., Li, M., \& Yin, R. (2016). Phytochemical content, health benefits, and toxicology of common edible flowers: A review (2000-2015). Critical Reviews in Food Science and Nutrition, 56, S130-S148. http://dx.doi.org/10.1080/10408398.2015.1078276.

Mak, Y. W., Chuah, L. O., Ahmad, R., \& Bhat, R. (2013). Antioxidant and antibacterial activities of hibiscus (Hibiscus rosa-sinensis L.) and Cassia (Senna bicapsularis L.) flower extracts. Journal of King Saud University - Science, 25, 275-282. http://dx.doi.org/10. 1016/j.jksus.2012.12.003.

Manthey, J. A., \& Guthrie, N. (2002). Antiproliferative activities of Citrus flavonoids against six human cancer cell lines. Journal of Agricultural and Food Chemistry, 50, 5837.

Middleton, E., Jr., Kandaswami, C., \& Theoharides, T. C. (2000). The effects of plant flavonoids on mammalian cells: Implications for inflammation, heart disease, and cancer. Pharmacological Reviews, 52, 673-751.

Miguel, M., Barros, L., Pereira, C., Calhelha, R. C., Garcia, P. A., Castro, M.Á., ... Ferreira, I. C. F. R. (2016). Chemical characterization and bioactive properties of two aromatic plants: Calendula officinalis L. (flowers) and Mentha cervina L. (leaves). Food \& Function, 2223-2232. http://dx.doi.org/10.1039/c6fo00398b.

Nadpal, J. D., Lesjak, M. M., Šibul, F. S., Anačkov, G. T., Četojević-Simin, D. D., MimicaDukić, N. M., \& Beara, I. N. (2016). Comparative study of biological activities and phytochemical composition of two rose hips and their preserves: Rosa canina L. and Rosa arvensis Huds. Food Chemistry, 192, 907-914. http://dx.doi.org/10.1016/j. foodchem.2015.07.089.

Nowak, R., Olech, M., Pecio, Ł., Oleszek, W., Los, R., Malm, A., \& Rzymowska, J. (2014). Cytotoxic, antioxidant, antimicrobial properties and chemical composition of rose petals. Journal of the Science of Food and Agriculture, 94, 560-567. http://dx.doi.org/ $10.1002 /$ jsfa.6294.

Oyaizu, M. (1986). Studies on products of browning reaction. Antioxidative activities of products of browning reaction prepared from glucosamine. The Japanese Journal of Nutrition and Dietetics, 44, 307-315. http://dx.doi.org/10.5264/eiyogakuzashi.44. 307.

Pereira, O. R., Peres, A. M., Silva, A. M. S., Domingues, M. R. M., \& Cardoso, S. M. (2013). Simultaneous characterization and quantification of phenolic compounds in Thymus $\times$ citriodorus using a validated HPLC-UV and ESI-MS combined method. Food Research International, 54, 1773-1780. http://dx.doi.org/10.1016/j.foodres.2013.09. 016.

Pires, T. C. S. P., Dias, M. I., Barros, L., \& Ferreira, I. C. F. R. (2017). Nutritional and chemical characterization of edible petals and corresponding infusions: Valorization as new food ingredients. Food Chemistry, 220, 337-343. http://dx.doi.org/10.1016/j. foodchem.2016.10.026.

Rakshit, S., Mandal, L., Pal, B. C., Bagchi, J., Biswas, N., Chaudhuri, J., ... Bandyopadhyay, S. (2010). Involvement of ROS in chlorogenic acid-induced apoptosis of Bcr-Abl + CML cells. Biochemical Pharmacology, 80, 1662-1675. http://dx. doi.org/10.1016/j.bcp.2010.08.013.

Shon, M. (2003). Antioxidants and free radical scavenging activity of Phellinus baumii (Phellinus of Hymenochaetaceae) extracts. Food Chemistry, 82, 593-597. http://dx. doi.org/10.1016/S0308-8146(03)00015-3.

Yang, Y., Sun, X., Liu, J., Kang, L., Chen, S., Ma, B., \& Guo, B. (2016). Quantitative and qualitative analysis of flavonoids and phenolic acids in snow chrysanthemum (Coreopsis tinctoria Nutt.) by HPLC-DAD and UPLC-ESI-QTOF-MS. Molecules (Basel, Switzerland), 21, 1307. http://dx.doi.org/10.3390/molecules21101307. 